\title{
DIY teaching manipulator
}

\author{
Manipulator dydaktyczny DIY
}

\section{MATEUSZ KRUCZEK PAWEK CHRZANOWSKI*}

DOI: https://doi.org/10.17814/mechanik.2022.3.3
The purpose of this paper was to present the results of a DIY teaching manipulator project. The design-construction process, selection of ready-made elements, design of control layer and 3D printing execution were presented. The article schowed the synergy and adaptation of ready-made solutions needed in the education of, among others, future engineers. The developed workstation has met the assumed assumptions and can be successfully implemented as a solution in common use at a low cost.

KEYWORDS: manipulator, DIY, Arduino, 3D printing, manipulator control software

Celem artykułu było przedstawienie wyników projektu manipulatora dydaktycznego DIY. Opisano proces projektowo-konstrukcyjny, dobór gotowych elementów, projekt warstwy sterującej oraz wykonanie wydruku 3D. Artykuł prezentuje synergię oraz adaptację gotowych rozwiązań potrzebnych w edukacji m.in. przyszłych inżynierów. Opracowane stanowisko spełniło przyjęte założenia i z powodzeniem może zostać wdrożone jako rozwiązanie w powszechnym użyciu przy niskim nakładzie kosztów.

SŁOWA KLUCZOWE: manipulator, DIY, Arduino, druk 3D, oprogramowanie sterujące manipulatorem

\section{Wprowadzenie}

W dobie szybkiego rozwoju przemysłu istnieje ogromna potrzeba edukacji przyszłych inżynierów w zakresie automatyki i robotyki czy mechatroniki. Najlepszą metodą nauki jest połączenie wiedzy teoretycznej i praktycznej. Niestety, ze względu na wysokie koszty kształcenia dostęp do stanowisk dydaktycznych, zwłaszcza wyposażonych w manipulatory przemysłowe, jest ograniczony. Problem ten pojawia się już w technikach oraz na uczelniach wyższych. Podczas zajęć laboratoryjnych uczeń czy student ma limitowany dostęp do fizycznego sprzętu, na którym pracuje w kilkuosobowych grupach. W takich grupach możliwości dydaktyczne są niewystarczające.

Manipulator jest urządzeniem powszechnie stosowanym w przemyśle, potocznie nazywany jest mechanicznym ramieniem. Składa się kilku połączonych przegubami ramion i jest zakończony chwytakiem. Manipulatory stosowane są najczęściej w przedsiębiorstwach w celu automatyzacji procesów pro- dukcyjnych oraz wszędzie tam, gdzie występują niebezpieczne lub szkodliwe warunki dla zdrowia ludzkiego. Ma to na celu zastąpienie fizycznej pracy człowieka, takiej jak przenoszenie elementów, segregowanie, spawanie czy malowanie.

Manipulator składa się $\mathrm{z}$ trzech podstawowych układów [1-4, 7]:

- układu mechanicznego, który przenosi wszystkie obciążenia i definiuje gabaryty manipulatora; w skład układu mechanicznego wchodzą m.in.: przekładnie, napędy i elementy konstrukcyjne;

- układu sterowania - serca całego manipulatora - który integruje wszystkie części manipulatora, zarządzając nimi; w większości rozwiązań jest to mikrokontroler lub sterownik PLC umieszczony w szafie sterowniczej obok manipulatora; układ ten może się składać z elementów logicznych (jak sterownik) i wykonawczych (styczniki, przekaźniki);

- układu sensorów, który dostarcza informacji o aktualnym stanie manipulatora do układu sterowania; zazwyczaj są to enkodery umieszczone na ramionach manipulatora, które informują o aktualnej pozycji; dodatkowo wykorzystuje się różnego rodzaju czujniki, których zadaniem jest monitorowanie otoczenia manipulatora.

Chwytak jest niezbędnym elementem manipulatora. Jego zadaniem jest np. złapanie elementu w taki sposób, aby go nie uszkodzić, i wystarczająco mocno trzymać, aby nie wypadł. Mechanizm chwytaka realizuje następujące czynności:

- pobranie elementu,

- stabilne trzymanie elementu w trakcie jego transportowania,

- uwolnienie elementu w miejscu docelowym.

$\mathrm{Na}$ rynku brakuje budżetowych stanowisk dydaktycznych wyposażonych w manipulatory [10-11] dostępnych dla techników oraz uczelni, zwłaszcza takich stanowisk, które bez trudu można przenosić. Większość stanowisk ma duże gabaryty i nie ma możliwości ich przemieszczania. Najczęściej zajmują one całą salę laboratoryjną, a w przypadku awarii lub remontów nie ma możliwości kontynuacji edukacji inżynierów. W związku z tym zaistniała potrzeba opracowania manipulatora dydaktycznego powszechnego użytku o niewielkich rozmiarach.

\footnotetext{
* Inż. Mateusz Kruczek - mateuszkruczek153@gmail.com, Polska Dr inż. Paweł Chrzanowski - pawel.chrzanowski@polsl.pl, https://orcid.org/0000-0002-8482-6170 - Katedra Podstaw Konstrukcji Maszyn, Wydział Mechaniczny Technologiczny Politechniki Śląskiej, Gliwice, Polska
} 


\section{Założenia wstępne}

Celem realizowanego projektu było zbudowanie stanowiska dydaktycznego $\mathrm{w}$ postaci manipulatora wieloosiowego, który będzie w stanie przenieść wybrane elementy z punktu początkowego do punktu końcowego. Dodatkowo całe stanowisko powinno zajmować niewiele miejsca oraz być łatwe w obsłudze.

Podczas realizacji projektu zdefiniowano podstawowe założenia:

- precyzję przenoszenia elementów - na potrzeby projektu przyjęto minimalną dokładność $\pm 2 \mathrm{~mm}$;

- całkowity koszt wykonania do 1000 zł, przez co rozwiązanie powinno być przystępne dla każdego;

- zwartość konstrukcji umożliwiającą wygodne przenoszenie manipulatora - o maksymalnych wymiarach $7000 \mathrm{~mm}$;

- maksymalny udźwig 100 g, który jest odpowiedni ze względu na małą masę elementów testowych;

- użycie standardowego zasilania z sieci $230 \mathrm{~V}$ z racji możliwości przenoszenia manipulatora;

- możliwość dalszej rozbudowy - łatwość modyfikacji w warstwie oprogramowania, sterowania, postaci konstrukcyjnej;

- na potrzeby dokładniejszej analizy oraz modyfikacji manipulatora powinien być dostęp do kodów źródłowych manipulatora oraz możliwość ich edycji; wskazane jest stosowanie istniejących rozwiązań;

- maksymalne wymiary przenoszonego przedmiotu sześcian o boku $30 \mathrm{~mm}$.

W wyniku przeanalizowania założonych kryteriów oraz dostępności podzespołów, materiałów i narzędzi do wykonania manipulatora przyjęto następujące elementy składowe urządzenia:

- metoda wykonania elementów konstruowanego manipulatora: druk 3D;

- napędy: serwomechanizmy MG995 oraz TowerPro MG-90;

- sterownik Polulu Maestro - umożliwiający precyzyjne sterowanie pozycją, prędkością oraz przyśpieszeniem serwomechanizmu; współpracuje z zastosowanym sterownikiem Arduino Mega (ATmega2560) za pośrednictwem magistrali komunikacyjnej RS 232; - wyświetlacz LCD z konwerterem LCD do magistrali 12C w celu wyświetlania aktualnej pozycji każdego napędu;

- sposób sterowania: aplikacja mobilna w smartfonie z systemem Android;

- moduł bluetooth HC-05 do komunikacji ze smartfonem,

- zasilanie: zastosowanie typowego zasilacza AC/DC, dzięki czemu zostanie spełniony wymóg zachowania bezpieczeństwa.

\section{Model i wykonanie manipulatora}

Do wykonania wirtualnego modelu manipulatora zastosowano oprogramowanie Autodesk Inventor [6]. W pierwszej kolejności pobrano gotowe modele CAD elementów/podzespołów przewidzianych do zakupienia. $\mathrm{W}$ internecie jest wiele portali $\mathrm{z}$ darmowymi modelami 3D. Producenci tych podzespołów oferują

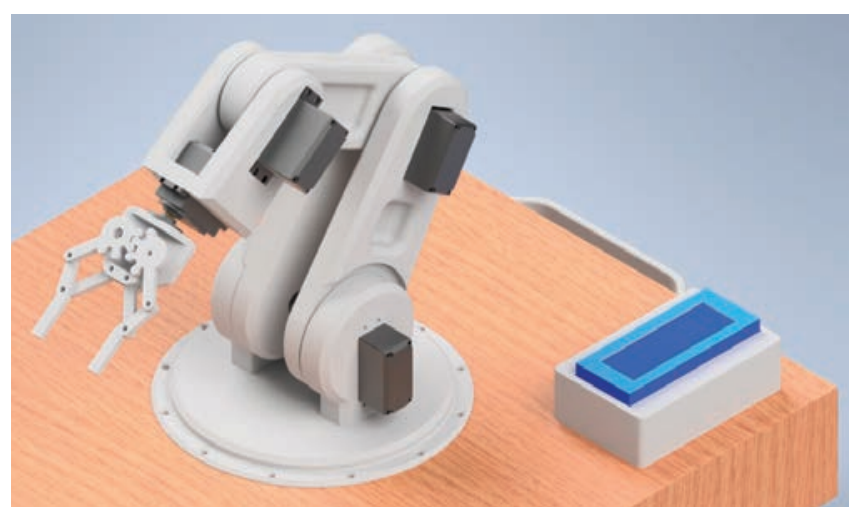

Fig. 1. DIY virtual manipulator model Rys. 1. Wirtualny model manipulatora DIY

również własne modele do zastosowania. Do gotowych podzespołów należą m.in. serwomechanizmy, łożyska oraz elementy łączące, np. śruby i wkręty. Ponadto przyjęto, że zostanie zastosowany gotowy model chwytaka udostępniony na stronach Thingiverse [13]. Chwytak ten charakteryzuje się małymi rozmiarami, niską masą oraz stosunkowo wysoką sprawnością, która pozwala na przenoszenie elementów. Chwytak może z powodzeniem przenosić elementy o masie kilkuset gramów oraz wymiarach $0 \div 4 \mathrm{~cm}$. Dodatkowo do projektu dodano silikonowe nakładki na elementy, które stykają się z przenoszonym obiektem w celu poprawy chwytu. Ze względu na swoje wymiary oraz możliwości przenoszenia elementów o wielkości kilku centymetrów dobrany chwytak spełnił założenia projektowe. Wykonany model 3D manipulatora przedstawiono na rys. 1.

\section{Druk 3D elementów manipulatora}

W celu wykonania modelu manipulatora użyto techniki szybkiego prototypowania, czyli druku 3D. Metoda ta pozwala na wyprodukowanie skomplikowanych elementów bez konieczności posiadania zaawansowanego parku maszynowego, a modele wyjściowe nadają się do użytku nawet prosto z linii produkcyjnej. Z racji posiadania drukarki Tronxy XY2- PRO większość elementów manipulatora została wydrukowana za jej pomocą. Z uwagi na brak grzanej komory w drukarce

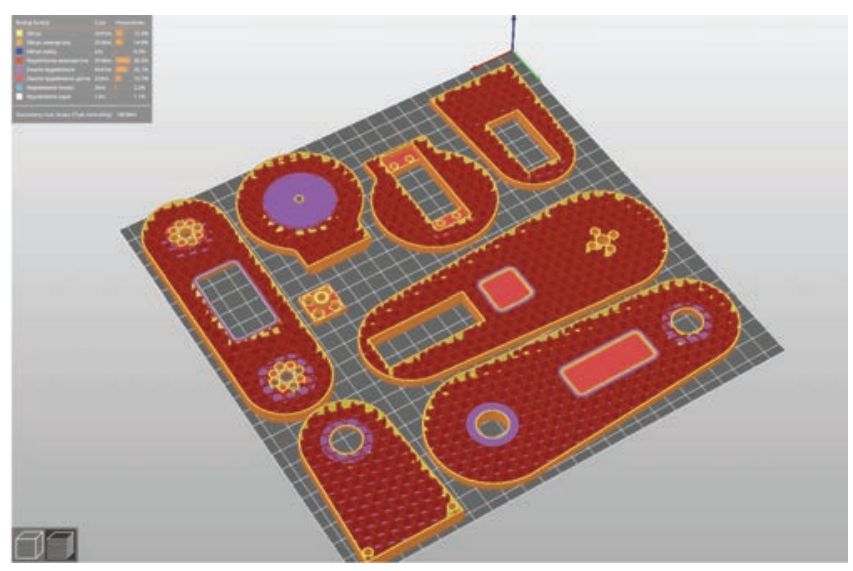

Fig. 2. View of manipulator components in preparation for printing at Prusa Slicer application

Rys. 2. Widok elementów manipulatora podczas przygotowania do druku w oprogramowaniu Prusa Slicer 
3D, rozważono użycie materiałów PLA oraz PET-G. Po przeanalizowaniu ich właściwości zdecydowano się wykonać model z PET-G ze względu na jego większą wytrzymałość mechaniczną. Zamodelowane w środowisku Autodesk Inventor elementy wyeksportowano do formatu .STL, a następie przygotowano model w oprogramowaniu Prusa Slicer (rys. 2).

\section{Układ sterowania}

W dalszej części realizacji projektu wykonano schemat sterowania (rys. 3) za pomocą darmowego środowiska Fritzing [8]. Następnie z użyciem uniwersalnej płytki zbudowano zgodnie ze schematem moduł sterowania wraz zasilaniem.

\section{Oprogramowanie}

Na potrzeby realizacji oprogramowania opracowano schematy blokowe w środowisku Visual Paradigm online wersja darmowa [12] dla:

- głównego modułu sterującego manipulatorem, w którym zawarto deklaracje zmiennych, dołączenie bibliotek oraz główną pętlę sterującą;

- modułu pozycjonowania manipulatora;

- modułu rejestracji aktualnej pozycji manipulatora;

- modułu obsługującego wyświetlacz LCD, który wyświetla pozycję, prędkość oraz przyśpieszenie.

Przykładowy schemat blokowy dla mikrokontrolera przedstawiono na rys. 4. Do przygotowanych schematów opracowano oprogramowanie sterujące manipulatorem z użyciem sterownika Arduino Mega $\mathrm{w}$ popularnym środowisku Arduino IDE. Językiem programowania $w$ tym środowisku jest $\mathrm{C}++$.

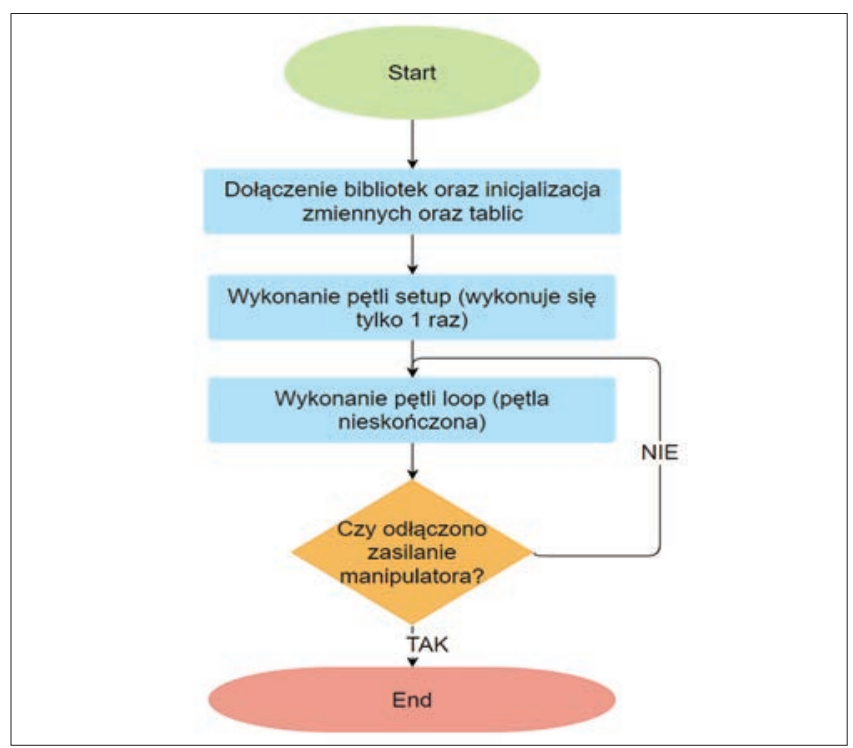

Fig. 4. Basic block diagram of microcontroller control Rys. 4. Podstawowy schemat blokowy sterowania mikrokontrolerem

\section{Aplikacja mobilna}

$\mathrm{Na}$ potrzeby sterowania manipulatorem konieczne było opracowanie takiego rozwiązania, aby nie powodowało wzrostu kosztów zestawu DIY. Zastosowanie smartfona z systemem Android do sterowania manipulatorem spełnia to kryterium. W internecie można znaleźć wiele gotowych aplikacji z otwartym kodem. Jedną z nich jest dokumentacja z kodami „How To Mechatronics" [9]. W wyniku weryfikacji tego kodu stwierdzono, że przy wykorzystaniu rozwiązań opisanych $w$ artykule aplikacja działała niestabilnie, a podczas sterowania występują długie odstępy czasowe

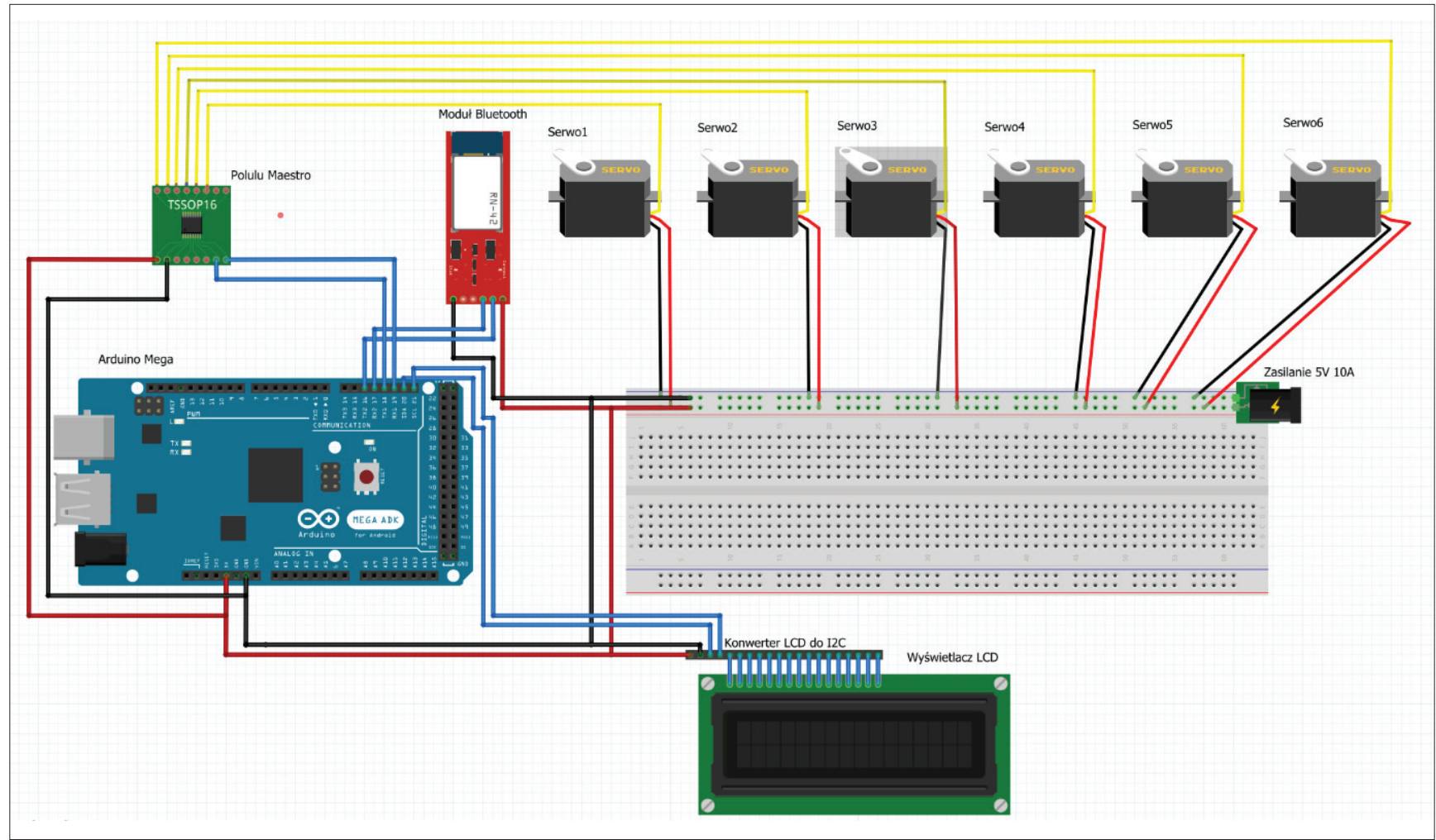

Fig. 3. Electrical diagram Rys. 3. Schemat elektryczny 


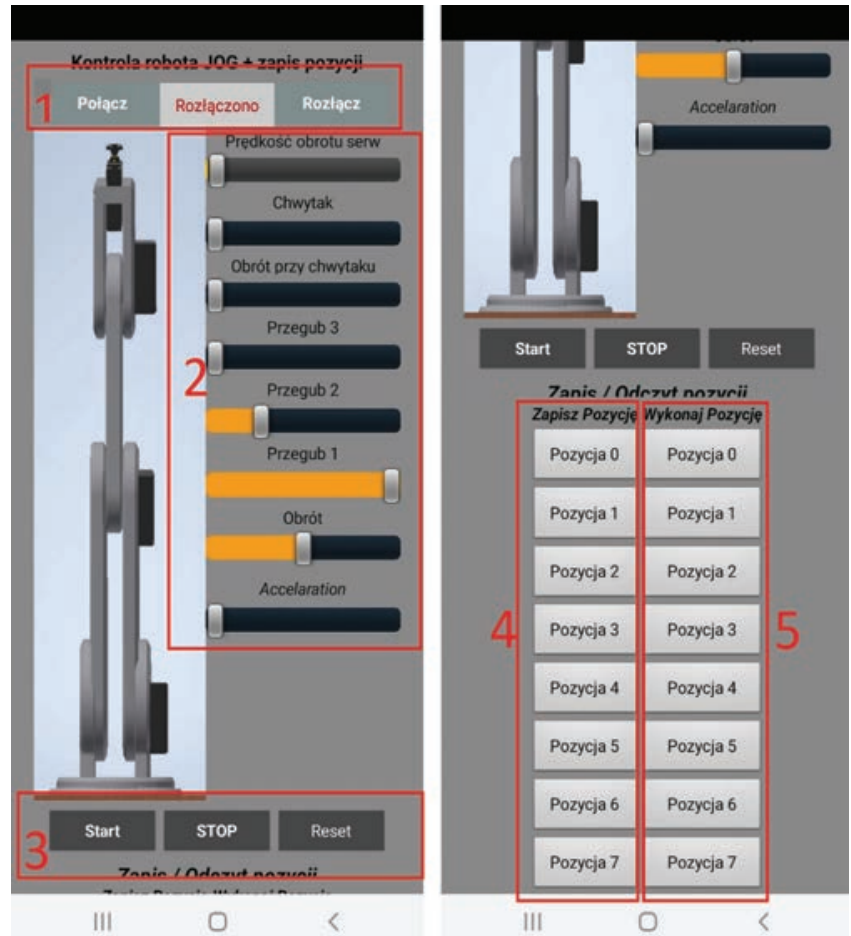

Fig. 5. Android control application [9]

Rys. 5. Aplikacja sterująca w systemie Android [9]

między akcją i reakcją. Błędy występowały ponadto podczas dłuższego przytrzymania przycisków (aplikacja wysyłała losowe sygnały). Jednak stwierdzone błędy $\mathrm{w}$ aplikacji oraz mikrokontrolerze udało się usunąć.

Środowisko MIT APP Inventor 2 [5], które jest obsługiwane przez smartfony z systemem Android, jest bardzo proste $\mathrm{w}$ zastosowaniu oraz przyjazne przy wprowadzaniu modyfikacji. Składa się z dwóch modułów: zakładki designer, czyli układania interfejsu graficznego z bloczków, oraz modułu blocs, gdzie zamieszczono całą logikę aplikacji w bloczkach funkcyjnych. Instalację aplikacji należało wykonać tak samo jak w przypadku innych aplikacji, np. ze sklepu Play dla systemu Android. Aplikacja instaluje się na smartfonie pod nazwą Robot Arm Control [9]. Ma kilka funkcji (rys. 5):

- Połącz/rozłącz: w górnej części aplikacji umieszczono przyciski, które odpowiadają za połączenie $\mathrm{z}$ odpowiednim urządzeniem bluetooth. Po wybraniu przycisku Połącz pojawia się okno wyboru urządzenia. Po kliknięciu w nazwę wybranego urządzenia aplikacja łączy się z nim. Przycisk Rozłącz odpowiada za zakończenie połączenia. Połączono/Rozłączono informuje o aktualnym statusie. Dodatkowo tekst zmienia kolor na zielony lub czerwony w zależności od stanu.

- Ręczne sterowanie przegubami, obrotem itp.: poprzez ruch suwakami można manualnie sterować manipulatorem. Dodana też została możliwość sterowania Prędkościq obrotowa serw oraz przyśpieszeniem (Acceleration). Aplikacja ma osiem suwaków, nad każdym suwakiem dodano komentarz, za co odpowiada.

- Sterowanie pracą automatyczną: z aplikacji mobilnej można uruchomić tryb automatycznej pracy manipulatora, zatrzymać go oraz wstrzymać jego pracę.
Przycisk Start rozpoczyna pracę automatyczną. Przycisk STOP oraz Reset kończą pracę automatyczną po wykonaniu cyklu.

- Zapisz pozycję: poprzez kliknięcie odpowiedniego przycisku można zapisać aktualną pozycję manipulatora w tablicy pozycji. W tym miejscu odbywa się zapis wszystkich pozycji. Dwie pierwsze pozycje zapisywane są do pozycji EEPROM, czyli ich dane nie są tracone po wykonaniu restartu sterownika. Resztę pozycji należy zapisywać po każdorazowym restarcie.

- Wykonaj pozycję: poprzez kliknięcie odpowiedniego przycisku następuje przemieszczenie do zapisanej pod danym przyciskiem pozycji.

\section{Weryfikacja stanowiska dydaktycznego}

W celu przetestowania stanowiska przeprowadzono ćwiczenie, które wykonuje się podczas szkoleń z manipulatorów, a mianowicie pick \& place, co oznacza: pobierz i umieść. W tym celu ustawiono na podstawie testową kostkę o boku $40 \mathrm{~mm}$. W pierwszej kolejności połączono aplikację mobilną z robotem za pomocą przycisku Połącz oraz wybrano urządzenie o nazwie HC-05. Kolejnym krokiem było zweryfikowanie poprawności przejazdu manipulatora w trybie ręcznym do każdej ze zdefiniowanych pozycji oraz odtworzenie ich w trybie automatycznym. Ruch ramion jest realizowany odpowiednimi suwakami (Przegub). Proces zapisywania pozycji rozpoczęto od pozycji 0 . Jest to pozycja bazowa manipulatora.

Po poprawnym ustawieniu manipulatora wybrano przycisk: Zapisz pozycję 0. Następnie zdefiniowano pozycję 1 - przyjazd do elementu. Po poprawnym ustawieniu manipulatora wybrano przycisk Zapisz pozycję 1. Kolejnym krokiem było zamknięcie chwytaka, czyli pozycja numer 2. Po poprawnym ustawieniu manipulatora zapisano pozycję 2 . Następną pozycją był

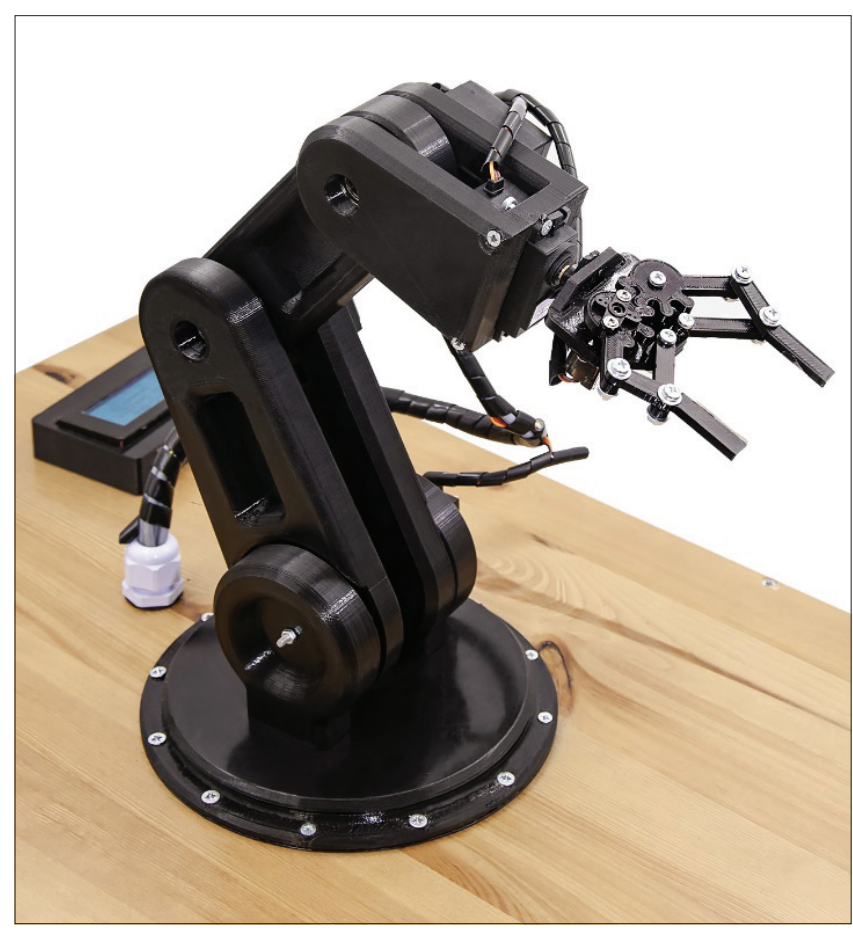

Fig. 6. Testing a DIY teaching manipulator Rys. 6. Testowanie manipulatora dydaktycznego DIY 
przejazd manipulatorem $\mathrm{w}$ dowolną pozycję pomiędzy początkiem a końcem trajektorii. Po poprawnym ustawieniu manipulatora zapisano pozycję 3. Pozycja numer 4 odpowiadała za odłożenie elementu. Po poprawnym ustawieniu manipulatora zapisano pozycję 4. Pozycja 5 otwiera chwytak. Po poprawnym ustawieniu manipulatora zapisano pozycję 5 . Pozycja numer 6 to odjazd manipulatora w bezpieczne miejsce, aby nie uszkodzić elementu. Po poprawnym ustawieniu manipulatora zapisano pozycję 6. Ostatnia pozycja to powrót do pozycji bazowej 0 . Po poprawnym ustawieniu manipulatora zapisano pozycję 7 .

Po zapisaniu wszystkich zdefiniowanych pozycji w trybie manualnym (uczenia) według opisanego planu ponownie uruchomiono manipulator w trybie automatycznym, wybierając w aplikacji przycisk Start. Manipulator rozpoczął pracę od pozycji startowej 0 , a następie po kolei wykonywał wszystkie pozycje od 1 do 7. Po zrealizowaniu planu powrócił do pozycji 0.

Przeprowadzona weryfikacja manipulatora oraz oprogramowania wypadła pomyślnie, gdyż kostka została przeniesiona zgodnie z zaprogramowaną listą od pozycji początkowej do pozycji końcowej.

\section{Wnioski}

Na rynku są gotowe rozwiązania manipulatorów typu DIY, jednak z uwagi na ich wysoki koszt, brak kodów źródłowych umożliwiających modyfikację czy też brak możliwości przenoszenia gotowego zestawu nie nadają się do szeroko pojętej dydaktyki w szkołach o profilach technicznych lub uczelniach wyższych kształcących przyszłych mechatroników, mechaników czy specjalistów z zakresu robotyki przemysłowej. Są to bardziej rozwiązania dla entuzjastów tych zagadnień.

Każdy, kto chce się nauczyć obsługi manipulatora, programowania, sterowania urządzeniami i pozycjonowania manipulatorów, ma możliwość opracowania własnego stanowiska edukacyjnego czy modyfikacji dostępnych rozwiązań darmowych. Przedstawiony projekt stanowi synergię pomiędzy dostępnymi darmowymi rozwiązaniami i spełnia wszystkie przyjęte założenia, takie jak: niski koszt wykonania, dostęp do kodów źródłowych oraz możliwość modyfikacji oprogramowania czy układu mechanicznego, a także stosunkowo kompaktowy rozmiar. Należy zwrócić szczególną uwagę na fakt, że stanowisko to może być podstawą do rozwoju na poziomie akademickim, obejmującego np.: wyposażenie w kamerę, rozpoznawanie obiektów, sortowanie albo klasyfikację obiektów. Przyszły inżynier może się również zapoznać z drukiem 3D, programowaniem sterowników, zastosowaniem specjalistycznego oprogramowania w zakresie CAD czy budowania prostych układów sterowania. Opracowana aplikacja sterująca działa tylko z systemami Android. W ramach rozbudowy stanowiska można opracować podobną aplikację na system IOS.

W dzisiejszych czasach łączenie teorii z praktyką jest nieodzowne, aby właściwie rozwijać kompetencje przyszłych inżynierów. Umiejętność wykorzystania wielu dyscyplin inżynierskich nabiera coraz większego znaczenia w edukacji, a świadczą o tym przedstawione wyniki projektu.

\section{LITERATURA}

[1] Lynch K., Frank C. "Modern Robotics: Mechanics, Planning, and Control". Cambridge: Cambridge University Press, 2017.

[2] Uransky M. "Modelling, Identification and Control of Robotic Manipulator". Saarbrücken: OmniScriptum GmbH \& Co. KG, 2014.

[3] Craig J. "Introduction to Robotics, Global Edition". London: Pearson Education, 2019.

[4] Hughes J. "Arduino: A Technical Reference". Massachusetts: O’Reilly Media, Inc., 2016.

[5] Kamriani F. "App Inventor 2 Essentials". Birmingham: Packt Publishing, 2016.

[6] Jaskulski A. „Autodesk Inventor Professional 2021 PL / 2021+ / Fusion 360. Metodyka projektowania". Gliwice: Wydawnictwo Helion, 2020.

[7] Szelerski M. „Robotyka przemysłowa. Teoria, budowa, eksploatacja". Krosno: Wydawnictwo Kabe, 2021.

[8] "FRITZING", https://fritzing.org/download (dostęp: 12.02.2022 r.).

[9] "DIY Arduino Robot Arm with Smartphone Control", https://howtomechatronics.com/tutorials/arduino/ diy-arduino-robot-arm-with-smartphone-control/ (dostęp: 22.01.2022 r.).

[10] "EEZYbotARM MK2", https://www.thingiverse.com/thing: 1454048 (dostęp: 28.01.2022 r.).

[11] "Robotic arm with 6 DOF", https://www.thingiverse.com/ thing:30163 (dostęp: 10.02.2022 r.).

[12] "Visual Paradigm online", https://online.visual-paradigm. com/ (dostęp: 10.02.2022 r.).

[13] "Thingiverse. Chwytak". https://www.thingiverse.com/ thing:2415 (dostęp: 10.02.2022 r.).

\section{Polub profil miesięcznika}

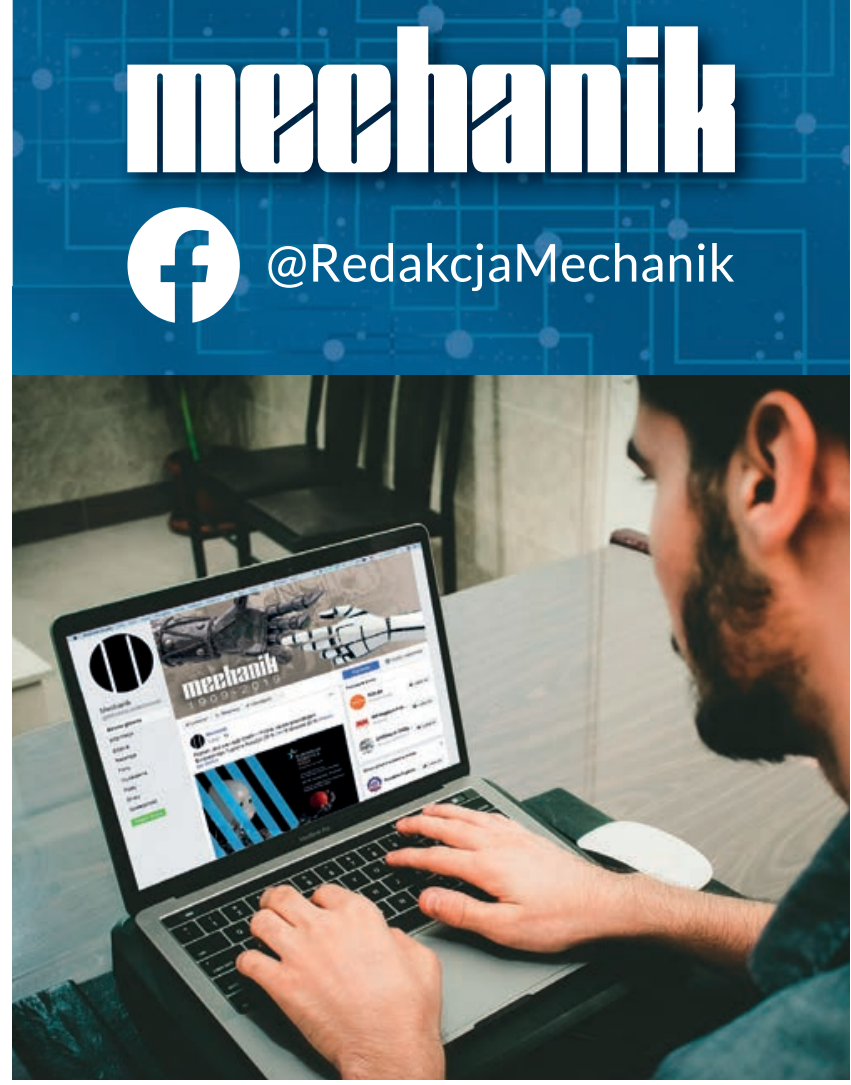

